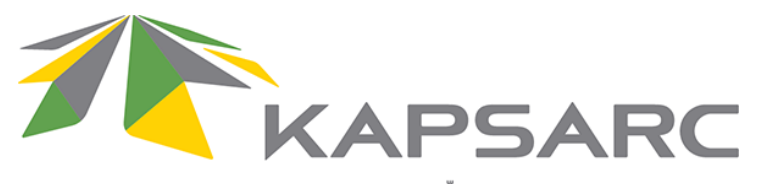

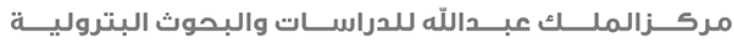

King Abdullah Petroleum Studies and Research Center

\title{
How coal fueled global growth and slowed energy productivity gains in the early 21 st century
}

Tarek Atallah and Jorge Blazquez 


\section{About KAPSARC}

The King Abdullah Petroleum Studies and Research Center (KAPSARC) is an independent, non-profit research institution dedicated to researching energy economics, policy, technology, and the environment across all types of energy. KAPSARC's mandate is to advance the understanding of energy challenges and opportunities facing the world today and tomorrow, through unbiased, independent, and high-caliber research for the benefit of society. KAPSARC is located in Riyadh, Saudi Arabia.

\section{Legal notice}

(C) Copyright 2015 King Abdullah Petroleum Studies and Research Center (KAPSARC). No portion of this document may be reproduced or utilized without the proper attribution to KAPSARC. 


\section{Summary for policymakers}

It is common for decision makers and media to conflate the oil price with the price of energy. High crude oil prices are taken as signals of energy scarcity. By contrast, and perhaps misleadingly, low crude oil prices are perceived as evidence of energy abundance.

The first decade of the 21st century was characterized by a strong growth in emerging markets, accompanied by a gradual and persistent increase in crude oil prices. Emerging markets grew at an annual average of $6.5 \%$ during 2000-2007. At the same time, oil prices grew at an annual average rate of $21 \%$. This increase in oil prices was a reflection of relative slow growth in crude oil production and rapid demand growth. However, these years were characterized by a relative abundance of energy from coal and, to some extent, natural gas. In particular, coal was the main source of the "additional energy" that fueled world economic growth during that period. This relative abundance of energy from coal and natural gas could partially explain why the increase in oil prices did not have as negative an impact on the global economy as many expected. On the contrary, the increase in the supply of coal and, to a lesser extent, natural gas could be one of the reasons that explains the acceleration in global economic growth in the period 2000-2007.

The increase in coal consumption led to a significant change in the energy mix. In 2000, coal only amounted to $29 \%$ of the total consumption. In 2012, the share of coal in the fossil fuel energy mix was $34 \%$, a level comparable to half a century ago. The shift in the world energy mix towards coal may be the result of a decrease in coal prices relative to oil and natural gas prices, complemented by accommodative policies in some key countries. Crude oil is still the largest source of energy, but the world has gradually been shifting towards more of a balance between oil, coal, and natural gas.

The surge in coal consumption appears to have impacted negatively on energy productivity growth, as coal use is less efficient than oil or natural gas from a technical and economic perspective. More energy from coal is required to achieve the same economic and calorific yield as is derived from oil. Despite an increase in energy productivity in key countries, the first years of the 21 st century saw global energy productivity growing more slowly than in the past. One reason for this is that emerging economies, which were less productive from an energy perspective, grew faster than advanced economies and increased their weight in the global average before their energy productivity had reached OECD levels.

Perhaps one conclusion to be drawn from the period 2000-2007 is that governments of emerging economies will not easily turn their backs on a source of energy that is affordable and reliable to drive economic growth. The relative costs of energy are as important to them as social, political, and environmental considerations in shaping the global energy mix. However, the other side of the coin is that the increasing exposure of the global economy to coal and natural gas means that oil may cease to be the only source of energy shocks or disruptions. Oil prices may no longer be the sole barometer of energy shortages or abundance. 


\section{Introduction}

Two observations can be made about energy markets regarding the first decade of the 21 st century.

- First, the real price of crude oil multiplied approximately fourfold from 1998 to 2008, without having as negative an impact on the global economy as some economists expected. This sharp increase in oil price appears to have played out differently than the crises of 1973 and 1979. It raises the question of why high fuel prices did not dampen global growth particularly during 2000-2007, a period characterized by the strong growth of emerging economies. On the contrary, global activity accelerated. During those years the Gross Domestic Product (GDP) growth of the world was $3.3 \%$, exceeding the $2.6 \%$ rate of the period 1991-1999. Year 2008 was characterized by a sharp deceleration of global growth. Many blame the international financial crisis for this decrease in global growth - high oil prices did not contribute much to it, according to Hamilton (2009).

One reason cited for the lack of impact on growth from high oil prices is that the surge in oil prices during 2000-2007 was the result of a strong increase in demand. Higher economic growth led to higher demand in oil and other raw materials, forcing an increase in their prices. By contrast, the crises of 1973 and 1979 were generated by a reduction in the supply of oil. Although some recent papers Blanchard and Gali (2008) and Kilian (2014) question the role played by crude oil in those crises, it is agreed that the reduction in supply aggravated the economic crises.

- The second observation is an apparent stagnation of global energy productivity after 2001. Energy productivity grew on average $0.1 \%$ during the period 2001-2013, while the average growth of productivity in 1971-2000 was $1.1 \%$. We define energy productivity as the amount of GDP achieved per unit of energy consumption. As Bean (2014) points out, energy productivity has a more positive connotation than energy intensity, is more intuitive, and can be directly aligned with efficiency. This slow rate of growth in energy productivity marked a new trend in data going back to 1970. Previously, the world has enjoyed a continuous rise in global energy productivity. Despite the sharp increase in the price of oil and strong economic growth between in 2000 and 2007, global energy productivity grew slowly after 2001 (as shown in Figure 1).

In this paper we suggest that these two observations the lack of the expected negative impact on economic activity of the last oil shock, and the slow rate of growth in energy productivity - are both consistent with a strong increase in the supply of coal and, to a lesser extent, in the supply of natural gas. During 2000-2007 consumption of crude oil increased by $12 \%$, natural gas increased by $22 \%$, and coal increased by almost $40 \%$. This resulted in a noticeable change in the fossil fuel mix. Coal represented $28 \%$ of the total fossil fuel consumption in 1999 , and it shifted to $32 \%$ in 2007 . The change of the energy mix towards coal continued and in 2012 amounted to $34 \%$ of the total fossil fuel consumption, comparable to the share of coal in the energy mix in 1969, according to the BP Statistical Review of World Energy.

The price of coal, relative to oil, has been decreasing since 2001 (we use a global price for coal, see Appendix I for a detailed description) providing an incentive for the increase in coal consumption. Figure 2 shows the evolution of relative prices and relative consumption of oil and coal.

Perhaps the shift of the world's energy mix and the surge in the production of coal had a macroeconomic 


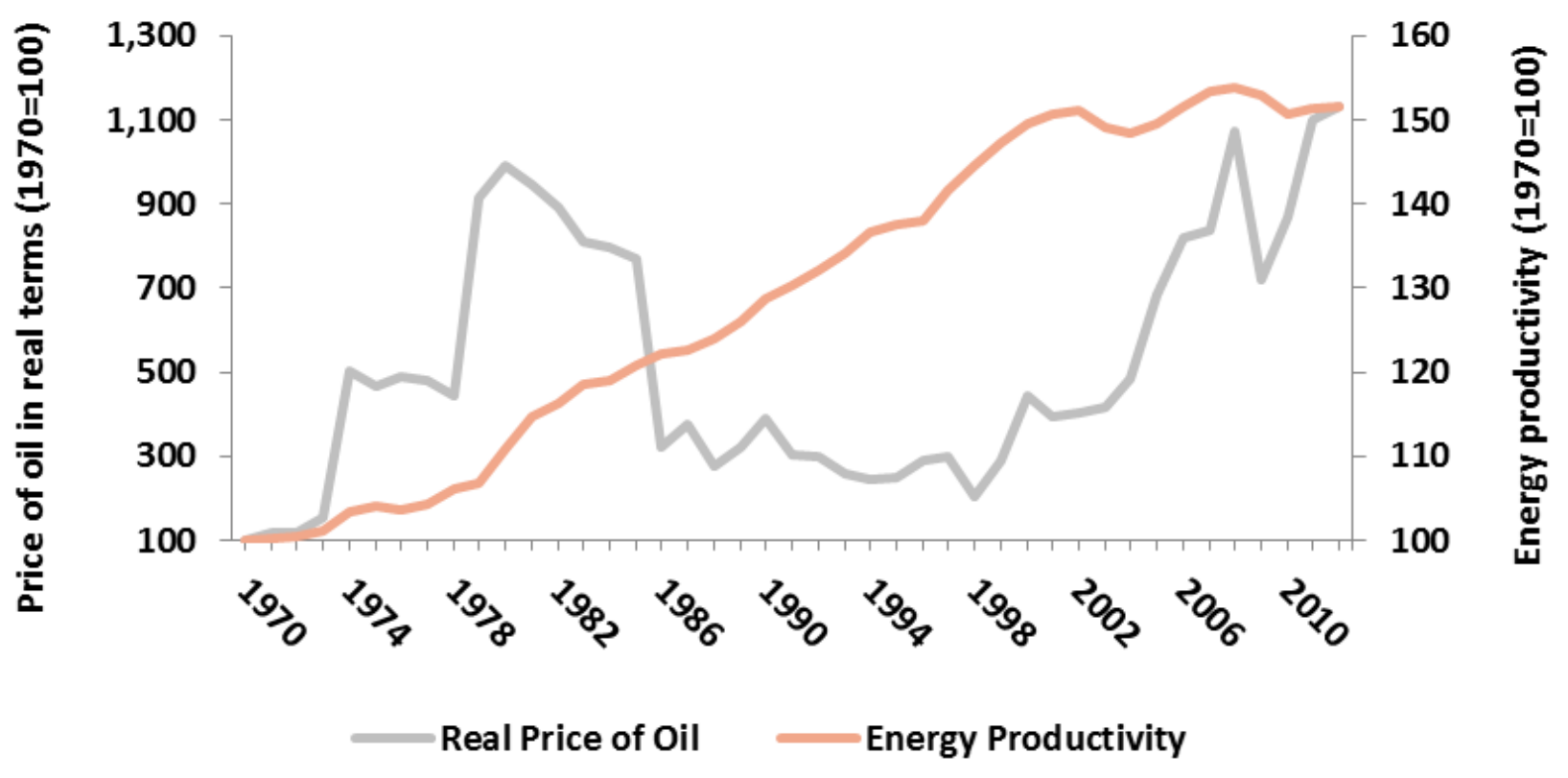

Figure 1: Evolution of energy productivity and primary energy prices (1970-2012)

Source: KAPSARC analysis and BP Statistical Review of the World Energy (2013)

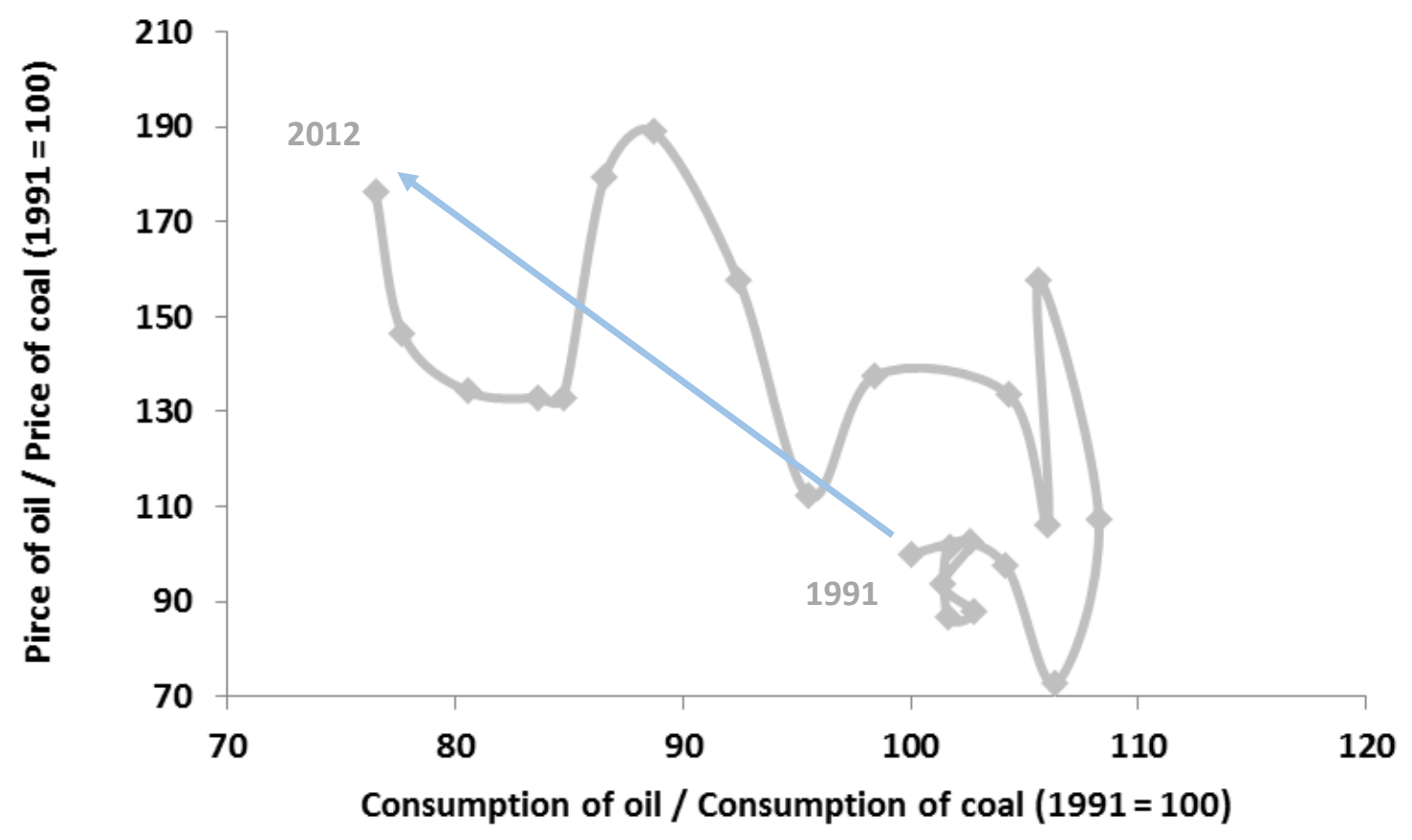

Figure 2: Evolution of energy productivity and primary energy prices (1970-2012)

Source: KAPSARC analysis and BP Statistical Review of the World Energy (2013) 
impact on global production in the first years of 21st century. Coal was the main source of "additional energy" during the years of 2000-2007 and may have offset the relatively slow growth of oil supply. Furthermore, it seems to have been a key fuel in sustaining the growth in global activity. However, from an economic and technical point of view, coal tends to be a less efficient source of energy than oil. This means that in order to generate a similar impact on economic activity, the economy needs more calorific units from coal than from crude oil. This could explain why the rate of growth of energy productivity seems to be increasing at a lower rate than in the past.

However, aggregate data on productivity can be misleading. There is an aggregation issue regarding the methodological approach to calculating world GDP: we can value GDP at market exchange rates (MER) or at purchasing power parity (PPP). The average rate of growth of global GDP at MER was $2.6 \%$ during 2001-2012, while it was 3.9\% for GDP at PPP. This makes a difference. The world's energy productivity increased annually by $0.1 \%$ using GDP at MER in the period 2003-2013 and it increased annually by $1.5 \%$ using global GDP at PPP. The International Energy Agency (2014) uses GDP at PPP for its report on energy efficiency, and this explains their insight that energy productivity has continued to grow. However, the difference between the two calculations is much less pronounced for richer, open economies than for poorer, less open economies - in some cases this is exacerbated by a lack of floating exchange rates. In the longer run, it can be expected that the divergence in the two measures will diminish as China and India, among others, enjoy continued economic growth and improved societal welfare. In our view, the long term nature of energy productivity targets suggests GDP at MER to be the more appropriate measure.
During 2001-2012 the world's energy productivity increased annually by only $0.1 \%$, but individual productivity in key countries increased. For example, energy productivity in China increased annually by $1.2 \%$ during those years, the US increased annually by $2.2 \%$, India increased by $1.5 \%$, and Germany increased by $1.6 \%$, respectively. This means that world's productivity growth slowdown is a result of the geographical composition of global growth. Less productive countries, from an energy demand perspective, are growing much faster.

Our analysis focused on fossil fuels only. Nuclear and renewable energies can be relevant in some countries, but they can still be considered supporting actors in the global energy market. Coal, natural gas, and oil amounted to $87 \%$ of the total energy consumption at the global level in 2012. During the period 2000-2007, according to BP Statistical Review, fossil fuel consumption increased by 1,881 Million tons of oil equivalent (Mtoe) while all other energy consumption increased by only 96 Mtoe.

\section{Description of the database}

In order to evaluate the role of coal in the global economy, we have developed a global database encompassing fossil fuel consumptions and prices from 1970 to 2012, although we focus our analysis in the years 1991-2012.

The database has been built using various sources. BP Statistical Review 2013 was the source for data regarding global and regional consumptions of coal, crude oil, and natural gas. These variables were all expressed in toe. It is important to mention that the BP database has some differences between global production and global consumption, but for simplicity, we assume that global consumption is equal to global production. See Appendix I for further details on the build-up of the database. 
In addition, macroeconomics indicators - such as nominal and real GDP at MER - were obtained from the World Bank database and the Penn World Tables.

Figure 3 summarizes the global price of fossil fuels in real terms from 1991 to 2012. It illustrates the notion that the real price of oil is more volatile than that of coal and natural gas. The standard deviation of oil price is 2.1 times larger than that of natural gas and 4 times larger than that of coal. Crude oil movements tend to be more abrupt than those of coal and natural gas. In addition, prices of different fuels seem to be largely positively correlated: when oil prices increase (or decrease), prices of natural gas and coal tend to increase (or decrease).
The database also reveals that, despite the decrease of oil in the world energy mix, crude oil represented $60 \%$ of the total expenditure in 2012, reinforcing that it is still the main source of potential economic disruption.

\section{A theoretical framework on energy consumption and global output}

We use an analytical framework to provide a quantitative explanation for the evolution of energy supply (and consumption) and its impact on global activity. However, this framework does not provide a comprehensive answer for the evolution of the global economy or energy markets.

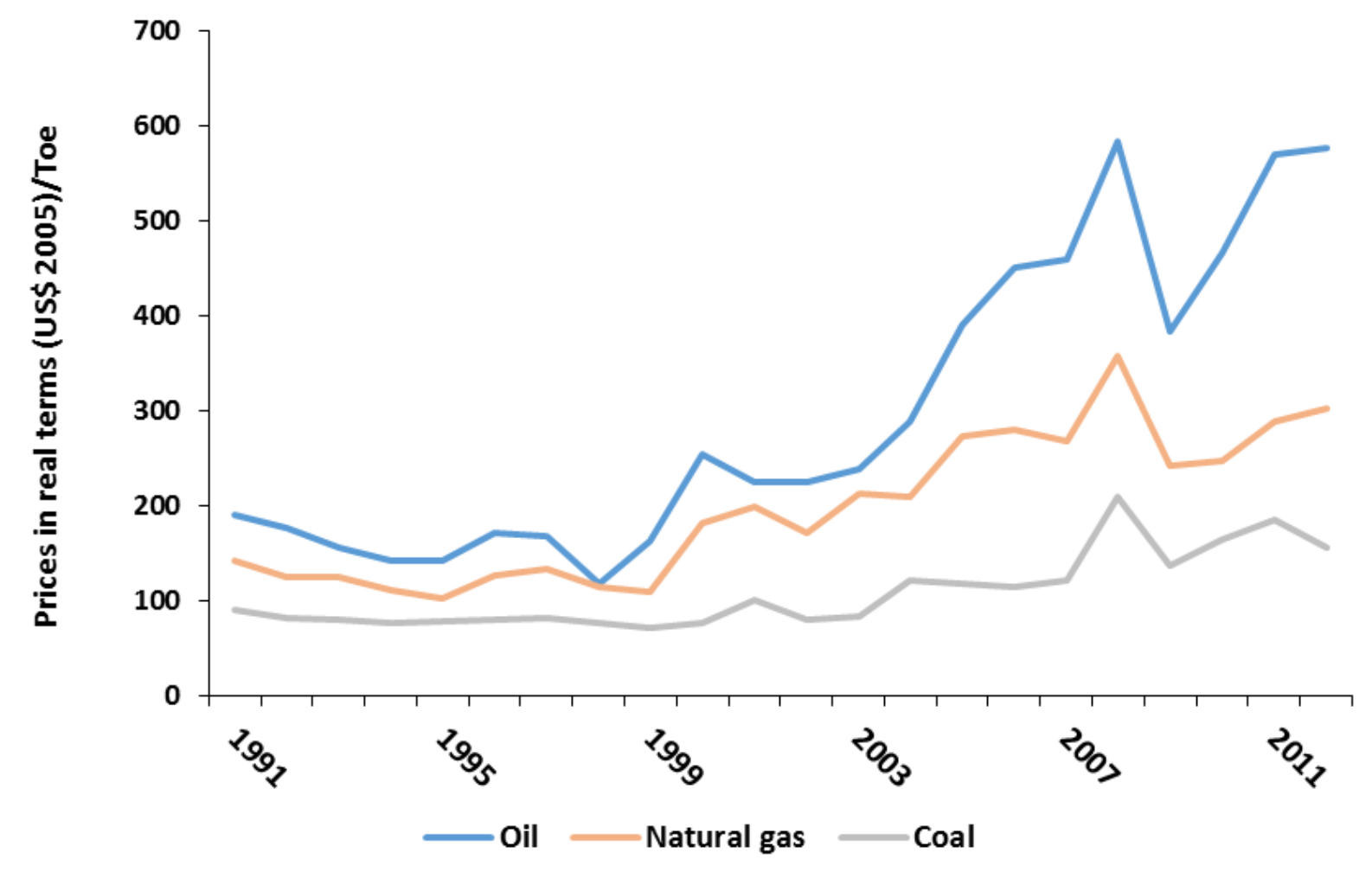

Figure 3: aggregated prices of crude oil, natural gas and coal in real terms (1991-2012) Source: KAPSARC analysis 
We consider that there are only three primary sources of energy: crude oil, natural gas, and coal. As mentioned before, our framework does not take into consideration nuclear and renewable energy because these sources only represent $13 \%$ of the global primary energy consumption in the years 2000-2007.

From a calorific perspective, oil, natural gas and coal could be considered potential valid substitutes. In principle, a toe or a gigawatt hour can be equally derived from crude oil, coal or natural gas, albeit restrained by technological availability and thermal efficiencies.

However, such a comparison does not stand from an economic perspective. The economic value of a calorific unit varies depending on the source of the primary energy. Different pricing among crude oil, coal, and natural gas are attributed to physical and technical limitations, logistics, environmental and geopolitical reasons. Our framework tries to tackle some of these issues.

In our analytical framework, we assume that there are two competitive and representative firms both producing a non-primary energy product. The first firm produces an energy product labelled intermediate energy. This intermediate energy is produced using only two inputs, natural gas and coal. Coal and natural gas are both used in many industrial processes and they compete in the production of electricity. For this reason, we model jointly coal and natural gas (instead of oil and coal or oil and natural gas). In addition, we assume that there is another energy product that we define as combined energy. Combined energy is generated using two inputs, crude oil and intermediate energy.

Finally, a competitive and representative firm produces global output, using as inputs combined energy (obtained from oil, coal and natural gas), labor and capital. The idea of combining energy, capital and labor in an aggregate production function is not new. De Miguel et al (2003, 2006), Acurio-Vasconez and Giraud (2012), Kemfert (1998) and Durand-Lassarve (2010) tackle this point using different approaches.

We point out that the elasticity of substitution among fuels is a key element for our production function and, hence, for the quantitative results that we obtain. Burniaux and Truong (2002) point out that the elasticity of substitution among fuels is very low in the short-term, but it increases in the long-term. We present results for two different parameterizations of the production functions. The first parameterization reflects a (low) elasticity of substitution among coal, natural gas and oil and intermediate energy of 0.5 in all cases. The second parameterization of characterization reflects a (high) elasticity of substitution among fuel of 1.0 in all cases. Burniaux and Truong (2002) suggest these elasticities.

Figure 4 shows the conceptual relationship among various inputs and outputs of our framework. Refer to Appendix 2 for a detailed explanation of the production function. Our results suggest that one additional toe of coal, natural gas or crude oil has a different impact on the global output. In the case of a low elasticity of substitution, and with actual data from 2011, the world economy can obtain $1 \%$ of additional combined energy - which is the energy relevant for global output growth - with an increase of $1.6 \%$ in oil consumption (all other inputs being equal), a $4.5 \%$ increase in natural gas consumption (all other inputs being equal) or a $7.5 \%$ increase in coal consumption (all other inputs being equal). Table 1 summarizes this point.

We want to stress that different production functions, or the same production functions with different elasticities of substitution, give different results. 
Contribution of fossil fuels to global growth in 2000-2007

Economic growth accelerated during 2000-2007. The average growth rate was $3.2 \%$, an increase of $0.5 \%$ percentage with respect to the $1990 \mathrm{~s}$, as illustrated in Table 2. Table 2 shows the annual rate of growth of Global GDP, labor, capital, oil, natural gas and coal for the periods 1992-1999 and 2000-2007.

At first glance, it seems that additional growth was fueled by a strong increase (acceleration) in coal production (from $0.4 \%$ to $4.5 \%$ ). However, this approach can be misleading. According to our theoretical approach, the world can "feed" economic growth using three different fossil fuels: oil, natural gas and coal. However, as we pointed out earlier, it is not possible to "replace or substitute" directly a toe of coal (or natural gas) for a ton of oil due to technical and economic restrictions. This means that direct growth rates of oil, natural gas and coal are not an accurate measure to assess their impact on economic growth.

A more accurate way of quantifying the role of energy is assessing how much oil, natural gas and coal contributed to GDP growth. In this sense, the

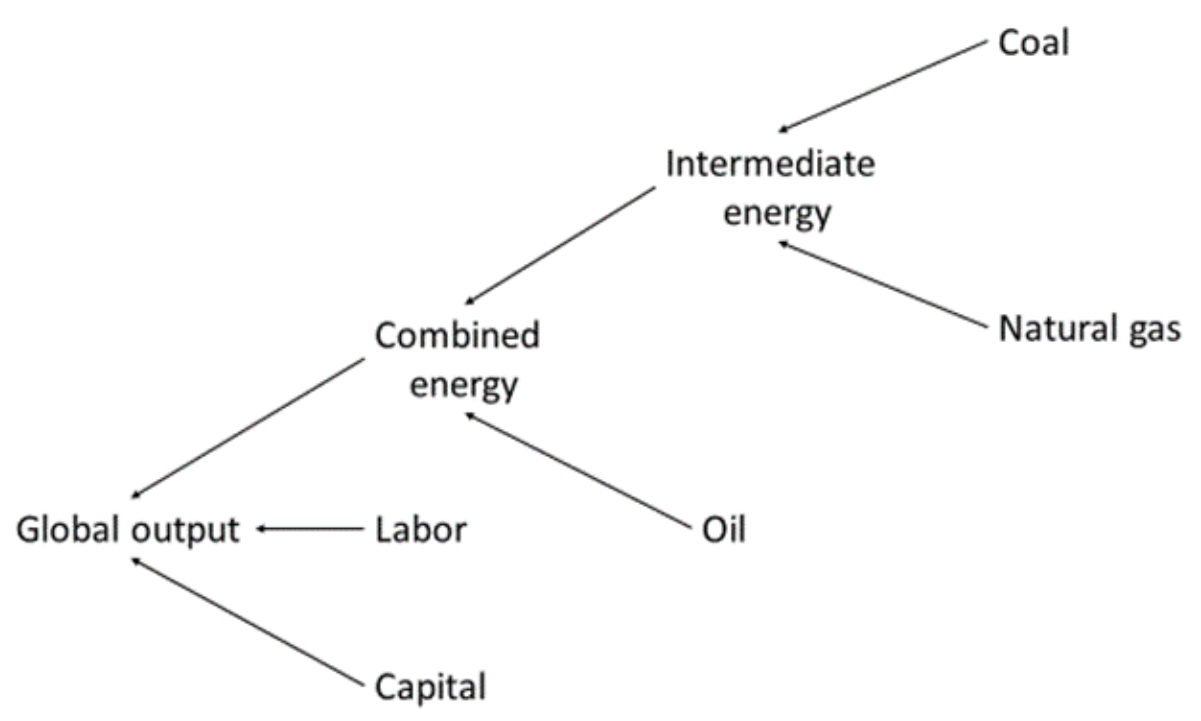

Figure 4: Graphical representation of the theoretical framework Source: KAPSARC analysis

\begin{tabular}{|c|c|c|c|c|c|}
\hline \multicolumn{2}{|c|}{ Low elasticity of substitution (0.5) } & \multicolumn{3}{c|}{ High elasticity of substitution (1.0) } \\
\hline Oil & Natural Gas & Coal & Oil & Natural Gas & Coal \\
\hline 1.6 & 0 & 0 & 1.7 & 0 & 0 \\
\hline 0 & 4.5 & 0 & 0 & 3.9 & 0 \\
\hline 0 & 0 & 7.5 & 0 & 0 & 6.2 \\
\hline \\
$\begin{array}{l}\text { Table 1: Consumption needed to increase combined energy } 1 \% \text { (in \%) } \\
\text { Source: KAPSARC analysis }\end{array}$ \\
\hline
\end{tabular}


analytical framework presented in the previous section allows us to assess the contribution of each input to global output growth. Not surprisingly, as illustrated in Table 3, labor, capital, and Total Factor Productivity (TFP) are the main sources of economic growth in both time periods. For example, in 1992-1999 global outgrew by $2.8 \%$. Labor contributed to this growth by $0.61 \%$, capital contributed by $1.39 \%$ and energy contributed by $0.05 \%$. The difference $(0.64 \%)$ is attributed to an increase in total factor productivity. Obviously, the direct contribution of combined energy in both periods is small, given that the elasticity of energy to global output is only 0.04 . This implies that an increase in combined energy of $1 \%$ leads to an increase in global output of $0.04 \%$.
As an initial result, we must highlight that the contribution of combined energy to GDP growth almost doubled in the period 2000-2007. Looking at Table 4, it seems that there is no evidence of a restriction in energy supply in the years 2000-2007, despite the increase in oil prices at that time.

We should notice that energy shocks - from a macroeconomic level and using different approaches - have been largely identified with crude oil shocks. This is the case of Hamilton (1983 and 2009), Eastwood (1992), Hickman et al (1987), Saunders (1984), Kilian (2008), and Burbidge and Harrison (1984), among others. Our results suggest that, from a macroeconomic perspective, natural gas and coal could have a relevant impact on economic activity in addition to oil. In other words, a strong

\begin{tabular}{|c|c|c|c|c|c|c|}
\hline & $\begin{array}{c}\text { Global } \\
\text { Output }\end{array}$ & Labor & Capital & $\begin{array}{c}\text { Crude } \\
\text { Oil }\end{array}$ & $\begin{array}{c}\text { Natural } \\
\text { Gas }\end{array}$ & Coal \\
\hline Period 1992-1999 & 2.7 & 1.3 & 2.9 & 1.4 & 1.8 & 0.4 \\
\hline Period 2000-2007 & 3.2 & 1.4 & 3.0 & 1.6 & 2.9 & 4.4 \\
\hline Change & 0.5 & 0.1 & 0.1 & 0.2 & 1.1 & 4.0 \\
\hline $\begin{array}{l}\text { Table 2: Average annual rate of growth of inputs (in \%) } \\
\text { Source: KAPSARC analysis }\end{array}$ & & & & & \\
\hline
\end{tabular}

\begin{tabular}{|c|c|c|c|c|c|}
\hline & $\begin{array}{c}\text { Global } \\
\text { Output }\end{array}$ & Labor & Capital & $\begin{array}{c}\text { Combined } \\
\text { Energy }\end{array}$ & TFP \\
\hline $1992-1999$ & 2.68 & 0.61 & 1.39 & 0.05 & 0.64 \\
\hline $2000-2007$ & 3.23 & 0.70 & 1.45 & 0.09 & 0.91 \\
\hline Change & 0.55 & 0.09 & 0.06 & 0.04 & 0.27 \\
\hline $\begin{array}{l}\text { Table 3: Contributions to GDP growth (in \%) } \\
\text { Source: KAPSARC analysis }\end{array}$ & & & & \\
\hline
\end{tabular}


increase (decrease) in the real price of oil does not necessary imply a shortage (abundance) of energy.

The following question is what explains the increase in the rate of growth of combined energy. In the analytical framework that has a low elasticity of substitution among fuels, we cannot perfectly adjust the contributions of each input because the production function is additive (the production function is a Constant Elasticity of Substitution CES) and there is a small discrepancy. In the case of the high elasticity of substitution, there are no mathematical discrepancies (the production function is a Cobb-Douglas).

Table 4 shows the average rate of growth of combined energy and the contributions from crude oil, coal and natural gas. For simplicity, we do not present the results for intermediate energy.

One observed highlight is that combined energy grew $2.4 \%$ in the period 2000-2007, much faster than in 1992-1999. Table 4 shows that oil was, by far, the main source of energy for the world economy, followed by natural gas. The contribution of coal to the growth of combined energy was negligible in 1992-1999, in contrast with 2000-2007 where its contribution increased notably.

Combined energy accelerated in $1.0 \%$ from one period to another. Results suggest that coal was the main input behind this acceleration and, to a lesser extent, natural gas. The contribution of oil to the "additional" combined energy was small compared to coal and natural gas.

These results support the idea that coal was the main source of "additional" energy during 2000- 2007. It also provides a possible answer to the question of why the increase in oil prices did not dampen economic growth. The increase in oil prices during the period 2000-2007 was a result of strong economic growth and relatively weak increases in oil supply, as depicted by Kilian (2009). However, it is not a reflection of energy shortage. Coal and, to a lesser extent, natural gas provided the energy needed to accelerate world economic growth.

There is an increasing consensus among economists that the world economy - or at least developed economies - is now less dependent on oil than it was in the 70s. Bernanke et al (1997), Leduc and Sill (2004) and Blanchard and Gali (2008) suggest that nowadays industrialized economies seem to be better prepared to manage and mitigate oil shocks. In our opinion, the shift in the energy mix towards coal and natural gas could partially explain why the world is less vulnerable to recent oil shocks.

\section{A possible explanation of why energy productivity growth is decelerating}

According to the data that we are using, we observe that energy productivity has seen an attenuated growth since 2001. The average growth of energy productivity was $0.1 \%$ during 2001-2013, while in the period 1991-2000 average annual growth reached $1.4 \%$.

We think that the shift in the energy mix towards coal is one of the reasons behind the apparent stagnation in global energy productivity in those years. As mentioned before, energy productivity is defined as the amount of GDP achieved per unit of energy consumption. Primary energy consumption is defined as the sum of the caloric units embodied in oil, coal, natural gas and other energies. However, and as we have described before, an additional toe of coal provides less combined energy than an additional toe of oil or natural gas. In our opinion, the "traditional macroeconomic approach" to energy productivity penalizes oil in favor of coal, given that they value the energy embodied in each commodity equally. To illustrate this point, we can compare the 


\begin{tabular}{|c|c|c|c|c|}
\hline $\begin{array}{l}\text { Low elasticity } \\
\qquad(0.5)\end{array}$ & Combined Energy & Oil & Natural gas & Coal \\
\hline 1992-1999 & 1.4 & 0.8 & 0.5 & 0.1 \\
\hline $2000-2007$ & 2.4 & 0.9 & 0.7 & 0.7 \\
\hline Acceleration & 1.0 & 0.1 & 0.2 & 0.6 \\
\hline $\begin{array}{l}\text { High elasticity } \\
(1.0)\end{array}$ & Combined Energy & Oil & Natural gas & Coal \\
\hline 1992-1999 & 1.4 & 0.8 & 0.5 & 0.1 \\
\hline $2000-2007$ & 2.4 & 0.9 & 0.8 & 0.7 \\
\hline Acceleration & 1.0 & 0.1 & 0.3 & 0.6 \\
\hline
\end{tabular}

actual evolution of energy productivity with the evolution of global GDP over combined energy (GDP/E), as illustrated in Figure 5. We can observe that, while energy productivity almost stagnates since year 2001, the variable GDP/E has increased at the same time.

The relative stagnation in the growth of energy productivity at a global scale is consistent with an increase in energy productivity in key countries. One possible reason for this observation is that emerging countries, which are less productive from an energy perspective, are growing faster than advanced economies. Individually, the productivity of each country may be improving, but collectively the world is not improving. The world productivity is slowly converging towards the level of productivity of emerging markets. Table 5 presents the evolution of energy productivity in key countries.
In addition, the evolution of global energy productivity depends on the methodology used to aggregate GDP from different countries. In this document we are using world GDP in real terms valued at MER. However, it is also possible to measure energy productive with world GDP in real terms at PPP. For example, the International Energy Agency (2014) reports on energy efficiency uses this approach. The evolution of productivity changes substantially depending on the choice of GDP calculation. As shown in Figure 6, the two measures of world GDP diverge substantially since the year 2000. Energy productivity using GDP at PPP grew on average $1.4 \%$ in the period 2001-2013 (lower than that of the period 1991-2000, 1.9\%). This contradicts the apparent stagnation of energy productivity at MER. However, the rate of growth of energy productivity using GDP at PPP is also decreasing. Productivity grew $1.1 \%$ in $2009-2013$. 


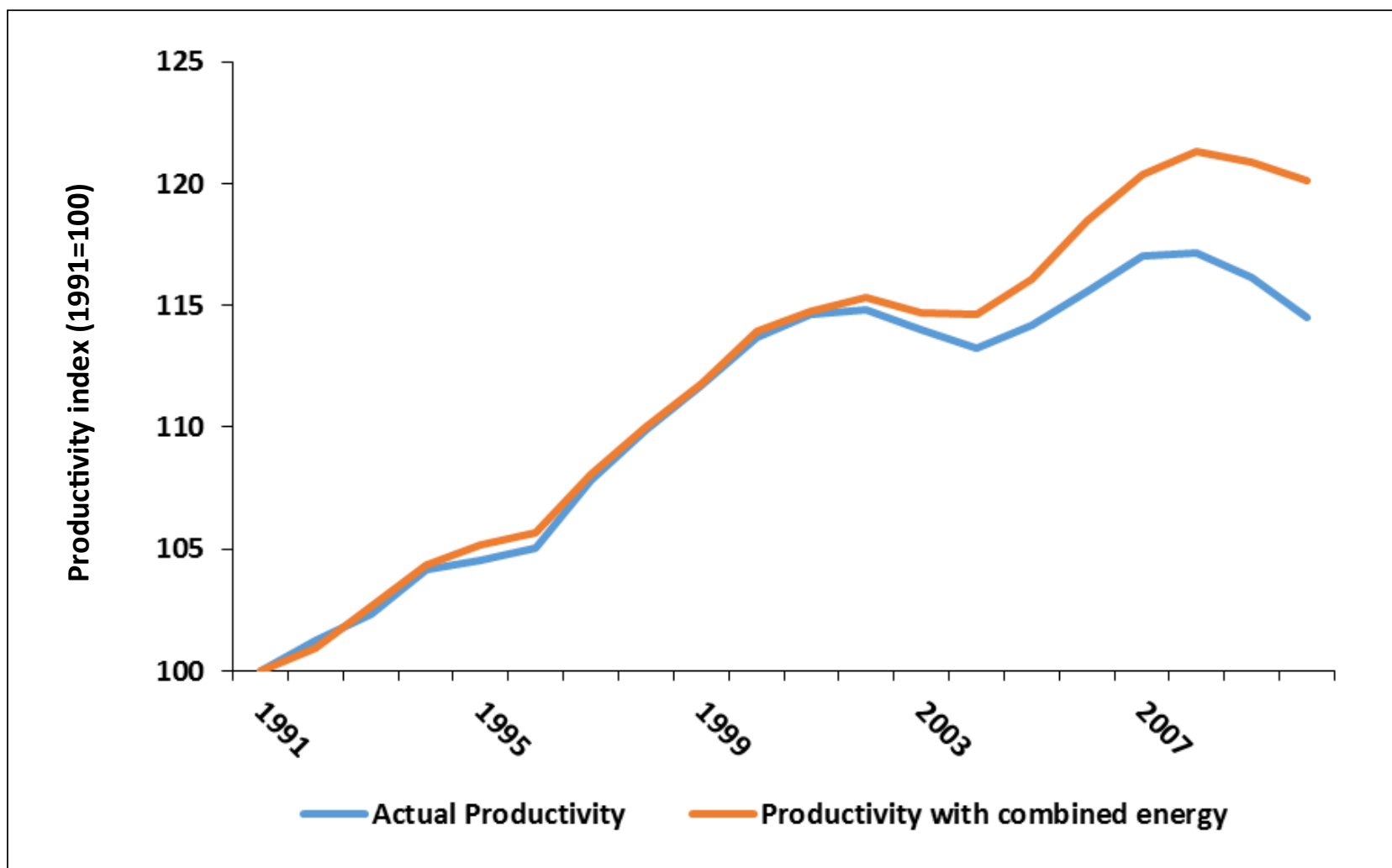

Figure 5: Energy productivity using GDP and combined energy (1991=100)

Source: KAPSARC analysis, data from BP Statistical Review of the World Energy (2013) and the IMF database

\begin{tabular}{|c|c|c|c|}
\hline Country & $\%$ & Country & \% \\
\hline China & 1.3 & Germany & -0.1 \\
\hline United States & 1.9 & Brazil & 1.3 \\
\hline India & 1.5 & Korea & 1.3 \\
\hline Japan & 1.5 & France & 1.3 \\
\hline World & & & \\
\hline
\end{tabular}

Table 5: Average increase in energy productivity from 2001 to 2013

Source: Data from BP Statistical Review of the World Energy (2013) and the IMF database 


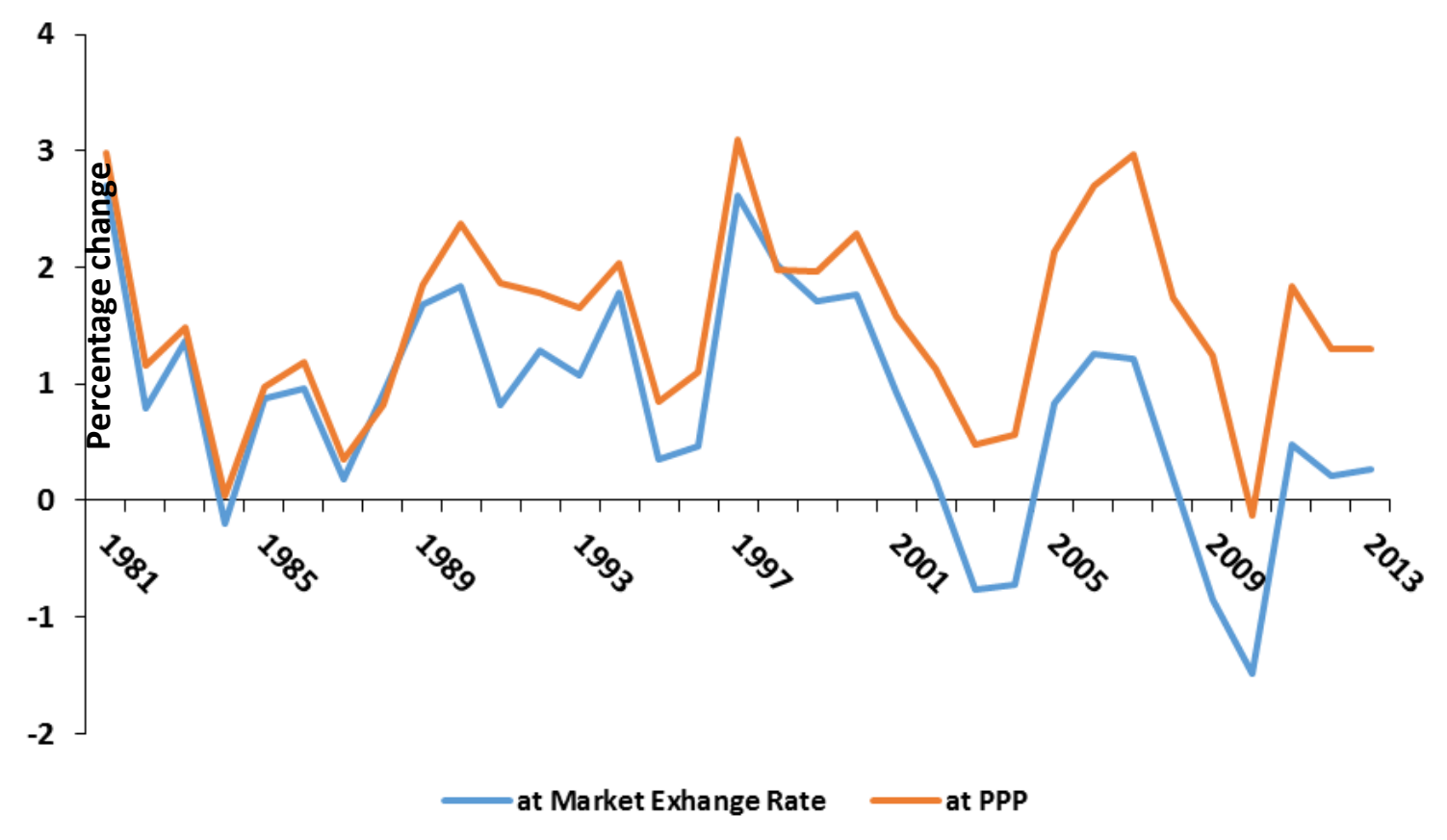

Figure 6: Energy productivity and gdp/combined energy (1991=100)

Source: Data from BP Statistical Review of the World Energy (2013) and the IMF database

\section{Conclusion}

Energy markets during the first decade of the $21 \mathrm{st}$ century were characterized by two intriguing observations: a sharp increase in oil prices without the expected negative impact on global growth, and a slower rate of growth of energy productivity. In addition, coal consumption increased around $60 \%$ between 2001 and 2012.

This sharp rise in coal consumption, and to a lesser extent in natural gas consumption, could be one of the factors that explains why the strong increase in oil prices did not have the expected negative impact on economic growth. The shift in oil prices reflected a strong increase in the demand of oil, but this cannot be directly interpreted as a shortage in energy supply. On the contrary, we suggest that the strong rise of coal production provided enough energy to accelerate global growth.
However, coal is less efficient - from a technical and economic perspective - than crude oil or natural gas. In other words, an additional calorific unit from coal has a lower impact on economic growth than an additional calorific unit from crude oil. This means that, in order to achieve a similar impact on economic activity, the world needs to consume substantially more coal than oil. According to our framework, a $4.6 \%$ increase in coal has a similar impact on economic activity (in terms of economic growth) than a $1 \%$ increase in oil.

In addition, global energy productivity could be growing at a slower pace. The shift in the energy mix towards coal could be one of the reasons for this slowing trend of energy productivity growth. This observation is consistent with an increase in energy productivity in key countries, such as China, the US, Japan, India, France or Germany. Emerging economies that are less efficient from an energy productivity perspective, are leading global growth but also damping energy productivity growth. 


\section{References}

Acurio-Vasconez, Veronica and Gael Giraud. "Energy and capital in a new-keynesian framework" Documents de Travail du centre d'Economie de la Sorbonne 92 (2012).

Bean, Patrick. "The Case for Energy Productivity: It's not Just Semantics". KAPSARC Discussion Paper KS-1402-DP01B.

Bernanke, Ben S., Gertlet, M. and Watson, M. "Systematic monetary policy and the effects of oil price shocks." Brookings papers on economic activity (1997): 91-157.

Blanchard, Olivier J., and Jordi Gali. 2008. "The Macroeconomic Effects of Oil Price Shocks: Why are the 200s So Different form 1970s?" In International Dimensions of Monetary Policy, edited by Jordi Gali and Mark j. Gertler. University of Chicago Press.

Burniaux, Juan-Marc and Truong P. Truong. "GTAPE: An Energy-Environmental version of the GTAP Model”. GTAP Technical Paper No. 16 (2002)

BP Statistical Review of the World Energy, June 2013.

Burbidge, John, and Alan Harrison. "Testing for the effects of oil-price rises using vector autoregressions." International Economic Review (1984): 459-484.

De Miguel, Carlos, Baltasar Manzano, and Jose Maria Martin-Moreno. "Oil price shocks and aggregate fluctuations." The Energy Journal (2003): 47-61.

De Miguel, Carlos, Baltasar Manzano, and Jose Maria Martin-Moreno. "Oil shocks and the business cycle in Europe". In Economic Modelling of Climate Change and Energy Policies. (2006) Edited by C. de Miguel, X. Labandeira and B. Manzano. Edward Elgar Publishing.

Durand-Lasserve, Olivier, Axel Pierru and Yves Smeers. "Uncertain long-run emissions targets, $\mathrm{CO} 2$ price and global energy transition: A general equilibrium approach". Energy Policy 38 (2010) 5108-5122.
Eastwood, Robert K. "Macroeconomic impacts of energy shocks." Oxford Economic Papers (1992): 403-425.

Hamilton, James D. "Oil and the macroeconomy since World War II." The Journal of Political Economy (1983): 228-248.

Hamilton, James D. Causes and Consequences of the Oil Shock of 2007-08. Brookings Papers on Economic Activity, Spring 2009.

Hickman, B., H. Huntington, J. Sweeney (Eds.), Macroeconomic impacts of energy shocks, NorthHolland, Amsterdam (1987)

International Energy Agency. Energy Efficiency Market Report, (2014).

Kemfert, Claudia. "Estimated substitution elasticities of a nested CES production function approach for Germany”. Energy Economics 20 (1998) 249-264.

Kilian, Lutz. "The Economic Effects of Energy Price shocks". Journal of Economic Literature (2008) 46:4: 871-909.

Kilian, Lutz. "Not all Oil Price Shocks are Alike: Disentangling demand and Supply shocks in the Crude Oil Market". The American Economic Review, Vol. 99, No. 3 (Jun., 2009), pp. 1053-1069.

Kilian, Lutz. 2014. "Oil Price Shocks: Causes and Consequences". London, Centre for Economic Policy Research. http://www.cepr.org/pubs/new-dps dplist.php?dpno=109823

Leduc, Sylvain, and Keith Sill. "A quantitative analysis of oil-price shocks, systematic monetary policy, and economic downturns." Journal of Monetary Economics 51.4 (2004): 781-808.

Saunders, Harry D. "The macro dynamics of energy shocks, short-and long-run." Energy economics 6.1 (1984): 21-34.

Penn World Tables version 8.0.

US Energy Information Administration. "Fuel Competition in Power Generation and Elasticities of Substitution". Independent Statistics \& Analysis, June (2012). 


\section{Appendix I: Description of the database}

Time series for fuel prices were generated, on a global and regional level, using national statistical institutions (such as the Chinese Bureau of Statistics) and international databases such as the US Energy Information Agency's (EIA) international database, Thomson Reuters' Datastream, the International Monetary Fund (IMF)'s World Economic Outlook, the World Bank Database, and BP's 2013 Statistical Review.

We computed an annual global price index for crude oil for the period 1970-2012 by dividing the world into five regions (Asia, Europe and Africa, North America, South America, and China). We selected a representative price in nominal US dollars for each of these regions. We opted for the West Texas Intermediate (WTI) obtained through the EIA database as the index price for crude oil in the Americas. Brent is the representative price for Europe and Africa, obtained from BP Statistical Review. As the BP database starts from 1976 onwards, we extrapolated the price for 1970 to 1975 by assuming a similar rate of growth between WTI and Brent. The assumption that the rates of growth of both Brent and WTI are the same is supported by the fact that crude oil is a freely tradable commodity, so different prices tend to move in parallel in the longrun. For China and the remainder of Asia, the Dubai blend price was chosen to be representative. The world price of oil is then calculated as the weighted average of the consumed oil in the five regions, multiplied by their corresponding price.

The natural gas price is constructed in a similar way. Henry Hub was taken as the representative price for North America and South America for 1990-2012, based on EIA's data. For the missing data points for the period 1970-1990, we used the gas wellhead price and linked both series, assuming that the rate of growth of both prices were identical. For the Asian markets, we have used the LNG landed price for Japan, provided by BP Statistical Review, as the benchmark price for the years 1984-2012. Previous years prices were calculated in a similar way as described for the American representative prices. The European price was assumed to be equal to the price of gas imported by Germany from Russia. This assumption is based on the fact that, despite having additional importing sources, like Algeria and Qatar among others, the European price will be ultimately converging to the Russian gas import price. Russia is by far the largest supplier for the European common market. As we lack data prior to 1984, the European gas price is generated using the prices provided the EIA for 1970-1983, assuming that both series have a similar annual rate of growth.

For the purpose of this study, the price of gas landed in Africa is assumed to be the same as the European one. This may be a counter-intuitive assumption that we had to undertake due to the limitation of the availability of data. This assumption seems fair, especially as the main African exporters, Algeria and Egypt, are both competing in the European market with the Russian gas. As for the crude oil global price, the world price of natural gas has been calculated by taking the weighted average of the consumed gas in the five regions multiplied by their corresponding price at delivery.

The case of coal is more complex. Coal is produced and consumed locally, and international markets are not as good a representation of coal prices as of oil and gas prices. In addition, natural gas and oil are much more homogenous commodities - from a pure physical and calorific perspective - than coal. The evolution of coal between 2000-2012 is shaped by China, meaning that is important for our analysis to have a country-specific 
coal price. China accounts for $85 \%$ of the total increase in global coal consumption for that period while amounting for $72 \%$ of the increase in the global coal production.

We have developed a price of coal for China. For the years 1999-2012, we used as benchmark the Qinhuangdao Thermal Coal price reported by Reuters. For 1980-1999, we used the Price Producer Index reported by the Chinese National Bureau of Statistics. We linked both series. Finally, for 1970-1979 and given the lack of information, we used the US Central Appalachian coal spot price index provided by the EIA. Again, we assumed that the Chinese coal and US coal both move in parallel during these years with identical rates of growth. For Europe and Africa, we use as benchmark the Northwest Europe marker price obtained through BP Statistical Review for 1987-2012. As in the previous cases, we generated missing data using the sea-born US Central Appalachian coal spot price as reference for price movements in Europe.

The Colombian coal was adopted as the benchmark for South America for 2000-2012, obtained from the World Bank database. For the rest of the period, we use the US Central Appalachian coal spot price as the reference for price movements in South America. In the case of Asia, the Australian price of coal provided by the International Monetary Fund is our benchmark and for years previous to 1980, the US is price used as the reference for price movements. Similar to the world price of natural gas and crude oil, the international price of coal has been calculated by weighting the average quantities of consumed coal in each regions multiplied by their corresponding price. Once we have the prices and the quantities of coal, natural and oil consumed, the total expenditure of the world in fossil fuel energy becomes pretty straightforward to obtain.

We must highlight that as we move back towards 1970 the accuracy of prices decreases.

\section{Appendix II: Detailed description of the production functions}

As mentioned previously, we use a simple analytical framework to provide a quantitative explanation on the evolution of energy supply and its impact on global activity in the first years of the 21 st century. However, this framework does not provide a comprehensive answer for the evolution of the global economy.

We consider that there are only three sources of energy: crude oil, natural gas, and coal. This framework does not take into consideration nuclear and renewable energy.

We assume that there are two competitive and representative firms that produce a non-primary energy product. The first firm produces an energy product labelled intermediate energy $\left(E^{*}\right)$. $E^{*}$ is produced by a representative firm that operates in a competitive market. The firm has a Constant Elasticity of Substitution (CES) technology of production with constant returns to scale. The function that relates the technology of production $E_{t}^{*}$ is expressed as:

$$
E_{t}^{*}=\left(b E g_{t}{ }^{\delta}+(1-b) E c_{t}{ }^{\delta}\right)^{\frac{1}{\delta}}
$$


This intermediate energy is produced using only two inputs, natural gas, $E g_{t}$ and coal, $E c_{t}$. The competitive firm maximizes its profits as defined by equation 2 below:

$$
\pi_{E^{*}, t}=P E_{t}^{*} E_{t}^{*}-P g_{t} E g_{t}-P c_{t} E c_{t}
$$

Where $\pi_{E^{*}{ }^{*} t}$ is the profit of the firm each period, $P E_{t}^{*}$ is the price of $E_{t}^{*}, P g_{t}$ the market price of natural gas and $P c_{t}$ the price of coal. It is important to mention that any firm that has a technology with constant returns to scale and that is operating in a market with perfect competition has no extraordinary profits. This leads that, in equilibrium, equation 3 below must hold.

$$
\pi_{E^{*}, t}=0 \Rightarrow P c_{t} E c_{t}+P g_{t} E g_{t}=P E_{t}^{*} E_{t}^{*}
$$

From the first order conditions, we can get following expression that links the demand of coal and natural gas.

$$
\frac{E g_{t}}{E c_{t}}=\left(\frac{b}{1-b} \frac{P c_{t}}{P g_{t}}\right)^{\frac{1}{1-\delta}}
$$

Where the parameter $\frac{1}{1-\delta}$ is the elasticity of substitution between coal and natural gas. Burniaux and Truong (2002) in their model use three different elasticity of substitution among fuel; 0.25 for the short term, between 0.5 and 1.0 for the medium term and 2.0 for the long run. For example, the US Energy Information Administration (2012) estimates an elasticity of substitution between coal and gas in the electricity sector around 0.15 . For illustrative purposes, we take a period of time of seven years (2000-2007) while considering an elasticity of substitution 0.5 and 1.0. Obviously, if the elasticity of substitution is 1.0, the production function is a Cobb-Douglas production function and the calibration process is straightforward. To calibrate the parameter " $b$ ", we get the average of the time series $\frac{E g_{t}}{E c_{t}}$ and $\frac{P g_{t}}{p_{c_{t}}}$ and then $\frac{1-b}{b}=\left(\frac{E c_{t}}{E g_{t}}\right)^{1-\delta} \frac{p_{c_{t}}}{P g_{t}}$
We calibrate " $b$ " as 0.58 .

Once we have the parameters of the CES production function, we can obtain an "observed" $E_{t}^{*}$ simply by substituting coal and natural with the actual values.

Secondly, we assume that there is another energy product that we define as combined energy or $E$. This combined energy is generated using two inputs: crude oil, $E o_{t}$, and $E^{*}$. As in the previous case, a representative firm produces $E$ in a competitive environment. The technology of production for $E_{t}$ is defined by a CES function with constant returns to scale in the form of:

$$
E_{t}=\left(a E o_{t}^{\gamma}+(1-a) E_{t}^{* \gamma}\right)^{\frac{1}{\gamma}}
$$

We use the same strategy as in the previous case. By considering choosing an elasticity of substitution of 0.5 , we calibrate " $a$ " to 0.68 . 
Once we have parametrized the CES production function, we can obtain the "observed" combined energy, $\widehat{E_{t}}$.

Finally, there is a production function for the world's global output, $Y_{t}$. Global output is produced from labor, capital and combined energy, $E$. As in the previous cases, we assume that there is a representative firm GDP that sells its products in a competitive market. The firm has a Cobb-Douglas technology of production with constant returns to scale as follow:

$$
Y_{t}=H_{t} L_{t}{ }^{\alpha} K_{t}{ }^{\beta} E_{t}^{1-\alpha-\beta}
$$

Where $Y_{t}$ is the world output, $H_{t}$ is a technological parameter, $L_{t}$ represents global labor, $K_{t}$ is the stock of capital and $E_{t}$ is the combined energy in period $t$.

The data for nominal and real GDP is the one reported by the World Bank (at MER). Labor values have been obtained from the Penn World Tables version 8.0, which also reports the "share of labor compensation in GDP at current national prices". The stock of capital has been calculated using an initial estimation of the stock of capital for the year 1970, the world gross capital formation (in billion USD) reported by the World Bank Database and using a depreciation rate of $6 \%$.

The calibration process is straightforward, since the parameters of labor, capital and combined energy are identical to the share of the expenditure of that input on total output. The parameters are the following: $\mathrm{a}=0.49$ and $\mathrm{b}=0.47$.

To summarize, global output is produced using labor, capital, oil, coal and natural gas according to the following production function:

$$
Y_{t}=H_{t} L_{t}{ }^{\alpha} K_{t}{ }^{\beta}\left(\left(a E o_{t}{ }^{\gamma}+(1-a)\left(\left(b E g_{t}{ }^{\delta}+(1-b) E c_{t}{ }^{\delta}\right)^{\frac{1}{\delta}}\right)^{\gamma}\right)^{\frac{1}{\gamma}}\right)^{1-\alpha-\beta}
$$




\section{About the team}

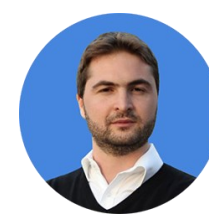

Tarek Atallah is a Senior Research Analyst evaluating energy productivity investments, economics of energy vulnerability, and the effect of climate on energy consumption patterns.

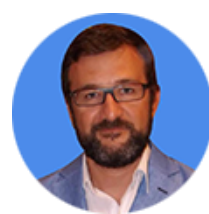

Jorge Blazquez is a Research Fellow specialising in energy and economics. He has a $\mathrm{PhD}$ in macroeconomics from Universidad Complutense de Madrid.

\section{About the project}

The KAPSARC Energy Vulnerability project looks at analyzing energy shocks and disruptions from the perspective of both exporting and importing economies. The project's objective is to understand what are the macroeconomic fundamentals that increase the resilience of a country to energy shocks and, in particular, the role of the energy mix in reducing vulnerability. The research will be complemented by an analysis of policies that enhance the resilience of economies to energy shocks. 